\title{
Coordinating Supply Chain Inventory Model for Deteriorating Products
}

\author{
M. Ravithammal, M. Babu, G. Rasitha Banu, P. Muniappan
}

\begin{abstract}
The paper manages an optimal inventory replenishment policy for a deteriorating item with two part coordination technique (coordination and non coordination). The aim of this model is to determine the optimal values for every strategy such that the expected total cost is minimized. The model is solved analytically to get the ideal solution. It is then outlined with the assistance of numerical models.
\end{abstract}

Keywords: Inventory, Order quantity, Deteriorating products, Coordination

\section{INTRODUCTION}

The EOQ and EPQ stock models have been utilized in numerous viable applications on the grounds that these stock models are basic and simple to actualize in associations. The sole goal of the model is to limit the complete stock related costs, normally holding expense and requesting cost. In many situations, these models don't think about the nearness of inadequate items in the part and modify of them. Also, these models have one significant element which is their vigor as for little changes in the parameters. In any case, the EOQ and EPQ stock models have a few presumptions that are exceptionally prohibitive. One of them is that the assembling procedure essentially creates great quality items. Truth be told, there are numerous circumstances practically speaking where the assembling procedure produces flawed items because of reasons, for example, aptitude level of the laborers, machine capacity, defective crude materials and upkeep arrangements.

Federgruen and Yang [1] created ideal inventory enhancement under general supply risks. Hemamalini et al. [2] read EOQ stock model for purchaser seller with screening, arranged expense and controllable lead time. Khan et al. [5] considered an incorporated store network model with blunders in quality review and learning in production. Khang and Fujiwara [6] examined optimality of myopic ordering policies for stock model with stochastic inventory. Mari Selvi et al. [8] contemplated seller purchaser incorporated stock model for controllable lead time with screening and arranged expense. Muniappan et al. [9]

Revised Manuscript Received on December 5, 2019.

M. Ravithammal, Assistant Professor, Department of Mathematics, The Quaide Milleth College for Men, Chennai - 600100, Tamil Nadu, India.

M. Babu, Assistant Professor, Department of Mathematics, Vels Institute of Science, Technology and Advanced Studies, Chennai-600117, Tamil Nadu, India.

G. Rasitha Banu, Assistant Professor, Department of Health Informatics, FPHTM, Jazan University, KSA.

P. Muniappan, Assistant Professor, Department of Mathematics, Sathyabama Institute of Science and Technology, Chennai - 600119, Tamil Nadu, India.

* Corresponding author: mail: mbabu5689@gmail.com investigated EPQ stock model for falling apart items including partially accumulated deficiencies. Jaber et al. [4] studied an entropic economic order quantity for things with defective quality. J. T. Hsu and L.F. Hsu [3] built up an EOQ model with imperfect quality things, examination blunders, shortage backordering, and deals returns. Khanna et al. [7] read vital creation displaying for defective items with defective investigation process, adjust, and deals return under two-level trade credit. Sarkar and Moon [10] investigated an EPQ model with expansion in a imperfect production system.

\section{ASSUMPTIONS AND NOTATIONS}

The model utilize the subsequent notations and assumptions

\section{Notations}

\section{Demand rate}

$r_{1}$ Unit ordering cost for Buyer

$\mathrm{r}_{2}$ Unit setup cost Vendor

$\mathrm{P}$ Production cost

$Q$ Economic Order Quantity

$h_{b}$ Unit holding cost Buyer

$h_{\text {EV }}$ Unit holding cost Vendor

$C_{g}$ Unit screening cost Vendor

$C_{d}$ Disposed cost

n Vendor's multiples of order

$s$ Shortage cost

k Buyer's multiples of order

d Discount factor

p Purchase cost

u. Percentage of defecting items

D Percentage of scrap items

\section{Assumptions}

(i) Demand rate is steady.

(ii) Vendor fabricates the items and buyer having shortage for non coordination technique.

(iii) For bulk purchase, vendor gives quantity discount to the buyer for coordination method.

(iv) Also, for coordination method buyer screened or disposed the harmed items and have no shortages and for non coordination method 
vendor screened or disposed the harmed items.

\section{MODEL FORMULATION}

\section{Case (i) : Non-Coordination Model}

In non coordination, the total cost for buyer contains following three costs

i) ordering cost $\frac{\mathbb{P}_{1} D}{Q}$,

ii) holding cost $\frac{h_{2} Q_{1}^{2}}{2 Q}$ and

iii) shortage cost $\frac{a\left(Q-Q_{1}\right)^{2}}{2 Q}$.

Now, the buyer cost will be written as

$T C_{B}=\frac{\nabla_{1} D}{Q}+\frac{R_{2} Q_{1}^{2}}{2 Q}+\frac{a\left(Q-Q_{1}\right)^{2}}{2 Q}$

In non coordination, the total cost for vendor contains following five costs

i) setup cost $\frac{m_{2} D}{n Q}$,

ii) holding cost $\frac{\hbar_{Y}[m-1 / Q}{2}\left(\frac{P-D}{p}\right)$,

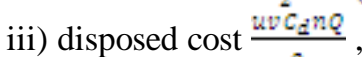

iv) screening cost $\frac{c_{x}^{2} \frac{2}{2}}{2}$ and

v) transportation cost $F+V Q$.

The vendor cost will be written as

$T C_{D}=\frac{x_{2} D}{n Q}+\frac{(n-1) \hbar_{Y} Q}{2}\left(\frac{P-D}{P}\right)+\frac{n \omega v C_{1} Q}{2}+\frac{C_{s} Q}{2}+F+V Q$

For optimality $\frac{\partial P C_{b}}{\partial Q_{1}}=0$ and $\frac{\partial^{2} P C_{b}}{\partial Q_{1}^{2}}>0$ and $\frac{B P C_{V}}{\partial Q}=0$ and $\frac{\partial^{2} T C_{V}}{\partial Q^{2}}>0$

we get, $Q_{1}^{*}=\frac{a Q}{a_{\mathrm{b}}+g}$ and

$Q^{*}=\sqrt{\frac{2 r_{2} D}{\left.\mathrm{n}\left[\varepsilon_{x}+(n-1) h_{2} \cdot \frac{F-D}{F}\right]+n w v C_{d}+2 V\right]}}$

Hence for non coordination the optimal order size is $Q^{*}=\sqrt{\frac{2 r_{2} D}{n\left[C_{x}+(n-1) h_{W}\left[\frac{F-D}{F}\right]+n w C_{d}+2 V\right]}}$ and the buyer and vendor costs are $T C_{b}^{*}$ and $T C_{E}^{*}$

\section{Case (ii): Coordination Model}

In coordination, the total cost for buyer contains following four costs
i) ordering cost $\frac{r_{1} D}{Q}$,
ii) holding cost $\frac{\mathrm{hb}^{2}}{2 Q}$,
iii) screening cost $\frac{\cos _{x} Q}{2}$ and
iv) disposed cost $\frac{w^{2} t_{n Q Q}}{2}$.

Now, the buyer cost will be written as

$T C_{B 1}=\frac{X_{1} D}{Q}+\frac{h_{b} Q^{2}}{2 Q}+\frac{C_{x} Q}{2}+\frac{w C_{A} M Q}{2}$

In coordination, the total cost for vendor contains following four costs

i) setup $\operatorname{cost} \frac{\mathbb{x}_{2} D}{n k Q}$,

ii) holding cost $\frac{h_{\mathrm{Y}} \mathrm{R}(\mathrm{T}-1) \mathrm{Q} Q}{2}\left(\frac{P-D}{p}\right)$,

iii) transportation cost $F+V Q$ and

iv) Discount factor $p D d$.

Now, the vendor cost will be written as

$T C_{\mathrm{WI}}=\frac{\mathrm{F}_{2} D}{\mathrm{gh} Q}+\frac{\mathbb{W}(\mathrm{m}-\mathbb{1}) \mathrm{h}_{\mathrm{Y}} Q}{2}\left(\frac{P-D}{p}\right)+F+V Q+p D d$

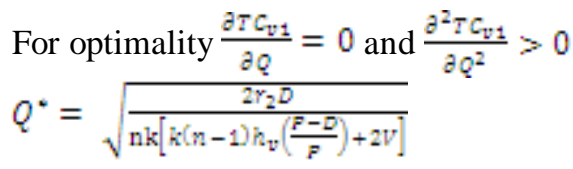

Hence for non coordination the optimal order size is $Q^{*}=\sqrt{\frac{2 r_{2} D}{\left.n k\left[R(n-1) k_{V} \cdot \frac{F-D}{P}\right]+2 V\right]}}$ and the buyer and vendor costs are $T C_{\mathscr{B}}^{*}$ and $T C_{\mathbb{1}}^{*}$

\section{NUMERICAL EXAMPLE}

Example 1: Let $\mathbb{R}_{1}=100, \mathbb{R}_{2}=400, D=1500, P=2500$, $\mathrm{H}_{\mathrm{w}}=0.03, \mathrm{H}_{\mathrm{b}}=0.02, \mathrm{C}_{\mathrm{s}}=0.1, \mathrm{~s}=0.25, \mathrm{C}_{\mathrm{d}}=0.6, \mathrm{u}=0.2$, $\mathrm{v}=0.1, \mathrm{p}=0.4, \mathrm{n}=2, \mathrm{k}=3, \mathrm{~d}(\mathrm{k})=10 \%, \mathrm{~F}=0.1, \mathrm{~V}=0.2$.

The optimal solutions are

Non coordination: $\mathrm{Q}^{*}=1066, \mathrm{Q}_{1}^{*}=987.04$,

$\mathrm{TC}_{\mathrm{b}}=150.58, \mathrm{TC}_{\mathrm{y}}=562.95$

Coordination: $\mathrm{kQ}^{*}=2314.6, \mathrm{TC}_{\mathrm{b} 1}=298.58$,

$\mathrm{TC}_{\mathrm{w}}=416.80$

Example 2: Let $\mathbb{R}_{1}=200, R_{2}=500, D=1000, P=1500$, $\mathrm{H}_{\mathrm{w}}=0.05, \mathrm{H}_{\mathrm{b}}=0.04, \mathrm{C}_{g}=0.1, \mathrm{~s}=0.25, \mathrm{C}_{\mathbb{d}}=0.6, \mathrm{u}=0.2$, $\mathrm{v}=0.1, \mathrm{p}=0.4, \mathrm{n}=2, \mathrm{k}=3, \mathrm{~d}(\mathrm{k})=10 \%, \mathrm{~F}=0.1, \mathrm{~V}=0.2$.

The optimal solutions are

Non coordination: $\mathrm{Q}^{*}=961, \mathrm{Q}_{1}^{*}=829.04, \mathrm{TC}_{\mathrm{b}}=224.56$, $\mathrm{TC}_{\mathrm{y}}=520.04$

Coordination: $\mathrm{kQ}^{\circ}=2070.2, \mathrm{TC}_{\mathrm{b} 1}=428.88$,

$\mathrm{TC}_{\mathrm{V} 1}=370.45$

\section{Conclusion}

In this paper, vendor - buyer EPQ model is created under coordination and non coordination circumstance. For coordination strategy purchaser screened or arranged the harmed things and have no deficiencies and for non coordination technique seller screened or arranged the harmed things. Under coordination, vendor gives quantity discount to the buyer for mass buy. Our point is to process the idea order quantity to minimize the total inventory cost. To contrast and non coordination, coordination circumstance demonstrates more advantages. For the further looks into, our proposed model can be stretched out into multilevel products, one time discount, price discount and temporary discount etc.,

\section{REFERENCES}

1. A. Federgruen, N. Yang, "Optimal supply diversification under general supply risks", Journal of Operations Research , 57(6), (2009), 909-925.

2. S. Hemamalini, M. Ravithammal, and P. Muniappan, "EOQ inventory model for buyer-vendor with screening, disposed cost and controllable lead time", AIP Conference Proceedings, 2095, (2019), $030001-030010$.

3. J.-T. Hsu, L.-F. Hsu, "An EOQ model with imperfect quality items, inspection errors, shortage backordering, and sales returns", International Journal of Production Economics, 143(1), (2013), $162-170$.

4. M.Y. Jaber, S. Zanoni, L.E. Zavanella, "An entropic economic order quantity for items with imperfect quality", Applied Mathematical Modelling, 37(6), (2013), 3982-3992.

5. M. Khan, M.Y. Jaber, A.R. Ahmad, "An integrated supply chain model with errors in quality inspection and learning in production", Omega, 42 (1), (2014), 16-24.

6. D. B. Khang, O. Fujiwara, "Optimality of myopic ordering policies for inventory model with stochastic supply", Operational Research, 48, (2000), 181-184.

7. A. Khanna, A. Kishore, and C. Jaggi, "Strategic production modeling for defective items 
with imperfect inspection process, rework, and sales return under two-level trade credit", International Journal of Industrial Engineering Computations, 8(1), (2017), 85-118.

8. A. Mari Selvi, M. Ravithammal and P. Muniappan, "Vendor-Buyer Integrated Inventory Model for Controllable Lead Time with Screening and Disposed Cost", Journal of Advanced Research in Dynamical \& Control Systems, 10(5), (2018), 636-638.

9. P. Muniappan, M. Ravithammal and A. Ameenammal, "EPQ incentive inventory model for deteriorating products involving partially backlogged shortages", Journal of Advanced Research in Dynamical \& Control Systems, 10(6), (2018), 940-943.

10. B. Sarkar, I. Moon, "An EPQ model with inflation in an imperfect production system”, Applied Mathematics Computations, 217 (13), (2011), 6159-6167. 